\title{
Influence of Habitat Conditions and Predation Risk ON PRODUCTIVITY AND BEHAVIOR OF A Partially-Migratory ElK Herd in the AbSaroka RANGE
}

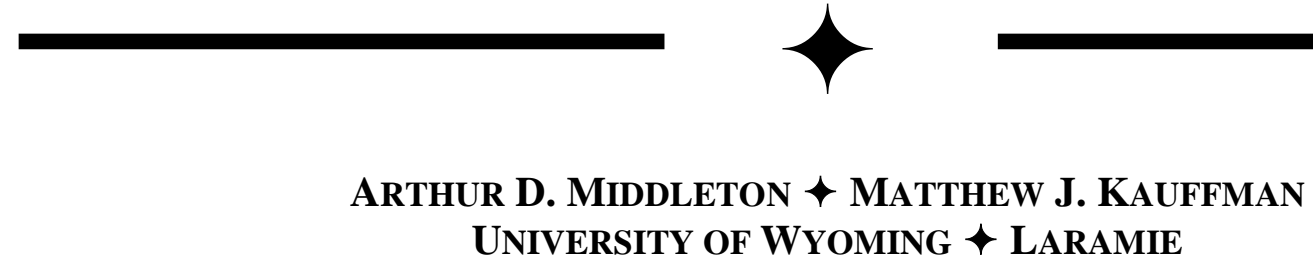

\section{$\uparrow \quad$ AbSTRACT}

Ungulate migration is an important but increasingly rare ecological process. Although Yellowstone National Park (YNP) retains a rich assemblage of migratory ungulates, changing ecological conditions across its boundaries are posing new and complex challenges to our understanding of migratory populations. This study is focused on the Clarks Fork elk herd, a partially-migratory population whose migratory subpopulation spends it summers in high-elevation alpine and subalpine habitats inside YNP's northeastern boundary. In the past decade, productivity of migratory elk has declined sharply while the non-migratory herd segment has remained stable or grown on private lands east of YNP. Early findings have revealed that pregnancy of migratory elk is exceptionally low, suggesting that YNP migrants are nutritionally stressed. Although fat gain in temperate ungulates is conventionally thought to be limited by summer forage quality, and the park has lately experienced prolonged drought, some have suggested that physiologically-costly, wolf-induced antipredator behaviors are reducing elk condition and reproductive performance. We are investigating the relative influence of habitat conditions versus antipredator behavior on the body-fat levels and reproduction of Clarks Fork elk. Our results will help YNP, the Wyoming Game and Fish Department (WGFD), the US Fish and Wildlife Service (USFWS), and other state and federal management agencies understand and manage elk populations and their migrations in the post-wolf reintroduction era.

\section{$\uparrow \quad$ INTRODUCTION}

Migratory elk inhabiting the Absaroka Range between Cody, Wyoming and YNP comprise an economically, culturally, and ecologically important wildlife resource ranging across multiple management jurisdictions. But several key trends among Absaroka elk are presently challenging managers' understanding and stewardship of this transboundary population. Historically, these elk were mostly migratory (Rudd 1982), but recently the proportion of migrants has declined. Based on study findings thus far, $70 \%$ of elk in the Clarks Fork herd now appear to reside year-round along the Absaroka Front, with only $30 \%$ migrating between winter range east of the Absaroka Divide and summer range in eastern YNP. These differences appear related to differential productivity of migratory and nonmigratory herd segments: over the past decade, WGFD has documented steeply declining calf production among migratory elk versus stable or increasing production among nonmigratory elk (Figure 1). Concurrently, the distribution of nonmigratory elk has shifted dramatically eastward onto private lands of the Absaroka Front.

Together, these changes pose numerous management and conservation challenges. For example, the expansion of nonmigratory elk causes crop damage and forage competition with domestic livestock and increases comingling of elk predators (i.e., wolves and bears) with livestock. In the longer term, a primarily nonmigratory life history could expose these elk to the consequences of private lands 
development. Meanwhile, the seasonal migrations of Clarks Fork elk represent a dwindling phenomenon among North American ungulates, and migratory elk are a prized game resource for the state of Wyoming. Prior studies suggest that several key ecological factors - namely calf predation, prolonged drought, and nonlethal, physiological effects of predation might be contributing importantly to reductions in calf recruitment.

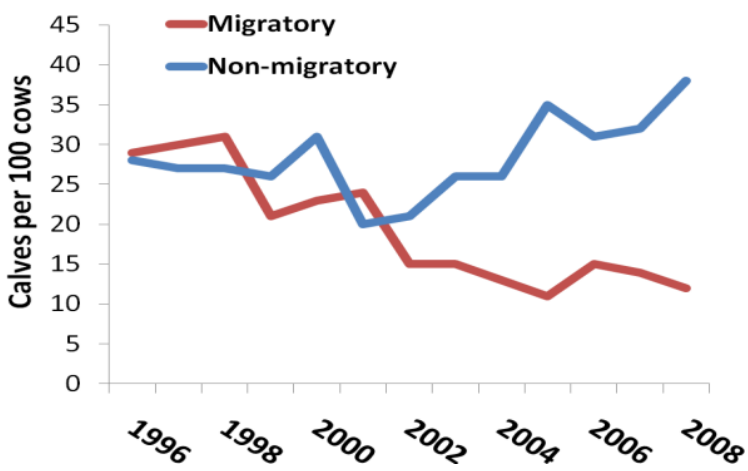

Figure 1. A gap in recruitment of migratory and non-migratory elk has widened dramatically in recent years.

Recent predation studies conducted by YNP and USFWS show selection for elk calves by grizzly and black bears in early summer (Barber-Meyer et al. 2008), and by wolves in winter (Smith et al. 2004, Jimenez et al. 2005). From 2003-2005, grizzly and black bears caused $58-60 \%$ of calf mortality among northern Yellowstone elk, with these mortalities occurring most heavily during the first 15 days of a calf's life (Barber-Meyer et al. 2008). Whereas nonmigratory Clarks Fork elk are typically found on private lands where bears and wolves are more heavily managed, migratory elk range harbors relatively high predator densities.

Beyond the direct effects of predation, however, our preliminary data suggest another important constraint on migrant elk productivity. While nonmigratory pregnancy has ranged from 84$100 \%$ over three years, migratory pregnancy is depressed at 59-75\%. In contrast, a recent review of pregnancy data from 25 Rocky Mountain elk herds found an average rate of nearly $90 \%$ (Raithel, et al. 2007, unpublished supplemental data). Furthermore, only one other herd fell below 70\%, and only six below $80 \%$. Coupled with WGFD recruitment trends, these unanticipated pregnancy data indicate that an underlying, acute nutritional stress limits migrant productivity.

Both drought and non-lethal effects of predation are hypothesized to influence pregnancy of large herbivores, and much of the existing research has been conducted in Rocky Mountain elk, including work by our collaborators John and Rachel Cook. Female elk in poor nutritional condition are known to experience a range of reproductive issues. Autumn body fat below $9 \%$ can hinder estrus and potentially increase fetal mortality (Cook et al., 2004a). Even when females become pregnant, poor condition might cause late calving or lower birth weight, reducing calf survival (Cook et al. 2004a). In the case of Absaroka elk, prolonged drought on YNP summer range might limit fat gain of migratory cows, while nonmigratory cows might benefit from access to irrigated crops along the Absaroka Front. Alternatively, however, nonlethal effects of predation might limit summer fat gain in spite of forage quality. Antipredator behaviors under high predator densities - including use of poor-quality refuge habitat and increased vigilance levels - are increasingly thought to carry physiological costs for prey species (Preisser et al. 2005), including Yellowstone elk (Creel et al.2007). Although this 'predator harassment' hypothesis has received popular interest and some scientific support within the GYE elk-wolf system, it has not been evaluated using marked animals of known habitat use and predator exposure. Our evaluation of this hypothesis comprises a novel and important contribution of this project.

In order to evaluate these two alternatives, the Absaroka Elk Project will biannually sample the body condition and reproductive status of 30-40 GPS-collared elk. A total of five recaptures will be conducted in late winter and early fall in order to estimate fat loss through winter and fat gain through summer. A 'pilot' recapture of 20 collared elk was successfully completed in March 2008, and unanticipated preliminary results emerged: Clarks Fork elk were the smallest-bodied of 16 North American herds previously sampled in late winter by John and Rachel Cook (unpublished data). On average these elk were $40 \mathrm{~kg}$ lighter than cows from neighboring northern Yellowstone (Cook et al. 2004b). Although further analysis is needed, it appears likely that nutritional stress is affecting Clarks Fork elk as calves and yearlings. Future recaptures will provide a wealth of additional information, and coupled with detailed sampling of wolf movements, elk habitat use, and summerautumn forage quality, these data will permit new investigation of the relative influence of habitat conditions versus wolf exposure on elk reproductive success. The results will inform the management of elk, wolves, and their shared habitat across a complex matrix of public and private range in northwest Wyoming. 
Repeated measures of elk condition, coupled with elk habitat selection and winter behavior observations, provide an additional opportunity to address the novel ecological question of how body condition mediates the strength of antipredator behavior in temperate large mammal systems. Despite clear evidence that temperate ungulates face strong inter-annual, seasonal, and spatial gradients in resource availability, research on large mammal behavior - including elk-wolf research in the GYE has neglected to evaluate how condition influences behavioral dynamics. Therefore, using estimates of body fat from marked individuals, we will ask how nutritional condition influences the strength of antipredator habitat selection and vigilance behaviors at the individual, herd segment, and population level. Whereas our current understanding of elk-wolf relationships and their community implications (i.e., trophic cascades) assumes a simple tradeoff between safety and foraging (Schmitz et al. 2004 Brown and Kotler 2004), ecological theory suggests a dynamic tradeoff, with the optimal behavior strongly determined by the internal state of the prey animal (reviewed in Houston and McNamara 1999, Clark and Mangel 2000). Most theory predicts that prey in poor condition will discount predation risk in favor of reducing the risk of starvation, while prey in good condition will be more responsive to predation risk (McNamara and Houston 1987, Abrams 1995, Luttbeg et al. 2003). These predictions are wellsupported by empirical studies across multiple vertebrate taxa in both aquatic (e.g. Vehanen 2003, Pettersson and Bronmark 1993, Krause et al. 1999) and terrestrial systems (e.g. Lima 1988, 1995, Bachman 1993; Sweitzer and Berger 1993), but have not been evaluated in a temperate large mammal system. Results from this work will test the ecological scaling of behavior-mediated trophic interactions among taxa, and introduce a muchneeded mechanistic perspective to the ongoing regional and national debate about the ecosystem effects of wolves.

\section{STUDY AREA}

The study area is determined by the seasonal movements of migratory and nonmigratory elk in the Clarks Fork elk herd. With the town of Cody, WY near its southeastern extent, the area encompasses approximately one million acres of mixed-use public and private lands at the northeastern frontier of the Greater Yellowstone Ecosystem. Its eastern boundary runs approximately from Cody to the town of Ralston, to include Heart Mountain, then shadows State Highway 120 north along the Absaroka Front to the Montana state line. The northern boundary follows the Montana line to include portions of the Beartooth Range and YNP that are used as summer range by the Clarks Fork herd. Inside YNP, the project area's eastern boundary follows Cache Creek to its confluence with the Lamar River; then runs southerly along the Lamar River to its headwaters at the YNP boundary. The southern boundary includes portions of the North Fork of the Shoshone River. This project area includes the entire Clark's Fork elk herd unit (HU217, Hunt Areas 50-54, 65, and 121). It also includes large public and private tracts of important big game, aspen, spruce-fir, and sagebrush habitats designated as priority areas in the WGFD's 2008 Strategic Habitat Plan.

\section{$\uparrow \quad$ METHODS}

Where necessary, project methods have been approved by the respective permitting authority or oversight committee. Animal capture protocols have been approved by the University of Wyoming's Institutional Animal Care and Use Committee (IACUC). Animal capture, vegetation sampling, and other work inside YNP is conducted under a permit obtained from the Yellowstone Center for Resources in summer 2008 (YELL-2008-SCI-5742), and renewed in 2009-10. Outside YNP, wolf captures are either conducted or authorized by USFWS, and likewise elk captures by WGFD.

\section{Elk habitat selection}

A total of 60 cow elk were captured on winter range in January 2007 via helicopter netgunning, and fitted with store-on-board GPS radio collars (Figure 2). Fifteen additional GPS collars were deployed in early 2008 to account for hunter mortalities; therefore, the project relies on a total sample of 75 GPS-collared elk. The collars are distributed evenly throughout migratory and nonmigratory herd segments. To evaluate elk habitat selection patterns, we monitor numerous environmental, weather, and precipitation variables. Temperature, wind direction and speed, solar radiation, and relative humidity are being gathered by permanent $(n=6)$ and portable $(n=2)$ Remote Automated Weather Stations. Snow depth and snow water equivalent information are collected at permanent Snotel sites $(n=10)$. After elk collars drop off in April 2010 and the movement data are obtained, a resource selection function (RSF) will be used to quantitatively analyze elk habitat selection as a function of habitat and predation variables (see below). 


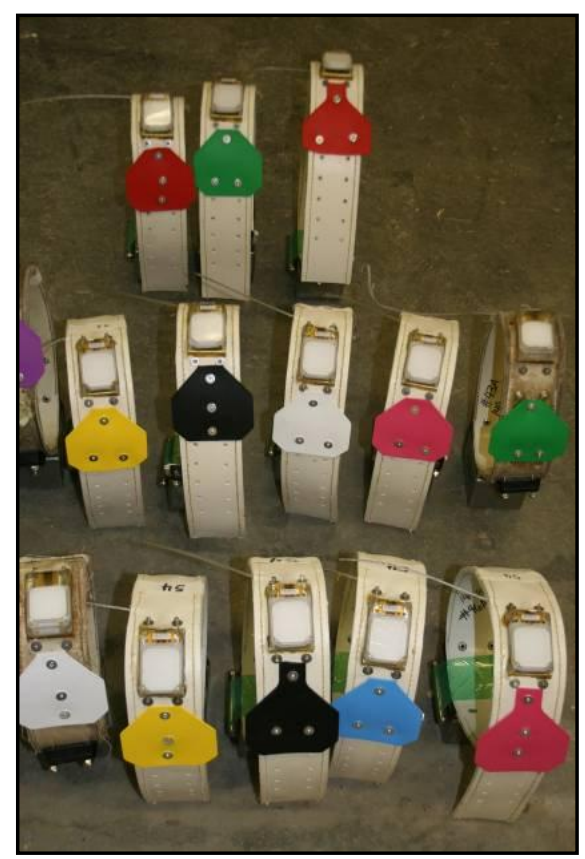

Figure2.

\section{Elk forage and dietary analyses}

During summers 2008-2010, through a companion study by Dr. Dan Tinker and M.S. student Sara Beaver in the UW Department of Botany, vegetation (Figure 3.) and fecal sampling will be conducted on summer range used by nonmigratory and migratory Clarks Fork elk. Habitat types used heavily by elk will be identified using USGS topographical maps and digital GIS vegetation layers. After locating groups of elk or recent elk sign, four study sites will be selected within each habitat type at least one kilometer apart. A $50 \mathrm{~m} \times 50 \mathrm{~m}$ plot will be randomly established within each study site. Three transects oriented in a N-S direction will be established along an E-W transect line at $0 \mathrm{~m}, 25 \mathrm{~m}$, and $50 \mathrm{~m}$. A $0.25 \mathrm{~m}^{2}$ quadrat will be placed at $5 \mathrm{~m}$ intervals along each transect, (total of 25 quadrats per plot) and the percent cover of each plant species rooted within each quadrat will be estimated to characterize the predominant vegetation present at each plot site, which serve as potential elk forage. Where possible, the percent of each plant species grazed will be recorded. Percent cover values $<10 \%$ will be estimated to the nearest one percent; percent cover values $>10 \%$ will be estimated to the nearest $5 \%$. Aboveground net primary productivity (ANPP) for each plant species will be calculated using scaling equations developed in YNP. ANPP will be estimated for each species and habitat type. Also at or near each plot, recent elk fecal material less than one day old will be collected for fecal nitrogen analyses to allow estimation of dietary protein. Following percent cover estimations, $100 \mathrm{~g}$ samples of the each of the four most abundant forb, grass, and shrub species will be collected. These samples will be returned to the laboratory at the University of Wyoming for processing. Nutritional analyses will include total nitrogen, total crude protein content, and total digestible nutrients.

\section{Wolf movements}

Through collaboration with USFWS the project maintains GPS movement coverage of wolf packs hunting elk in the Clarks Fork herd. In addition, YNP is providing data from 1-2 GPS collars in the Druid Peak Pack, which is known to hunt migratory Clarks Fork elk on summer range. In addition to habitat variables, wolf predation risk will be used as a variable in the elk habitat selection analysis. GPS collars on both elk and wolves are programmed to gather one location every three hours when elk are on either winter or summer range. To evaluate if wolves alter elk habitat use, we will score for each elk the presence or absence of a wolf pack within a specified distance. We will then determine if the elk selection strength for each habitat type is different on days when wolves are present or absent. Finally, we will estimate the forage quality of habitats used by elk on days with and without wolves to evaluate if elk are using poor-quality 'refuge' habitats when wolves are near. These calculations will make use of average estimates of forage quality for each habitat, derived from the fine-scale plant nutrition sampling described above.

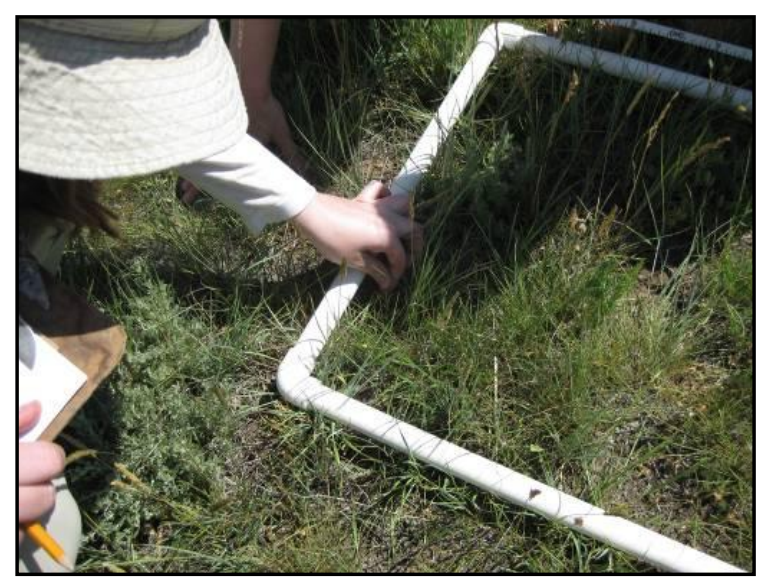

Figure 3.

\section{Elk body condition recaptures}

To relate habitat, forage quality, and wolf exposure to the condition and pregnancy rates of Clarks Fork elk, 30 previously-collared migratory 
and nonmigratory elk will be recaptured by helicopter darting twice each year until the end of field study in April 2010, for a total of five recaptures. Recaptures will be conducted in late winter and early fall, in order to determine fat loss through winter and fat gain through summer. The schedule of five recaptures will provide data for two summers' fat gain and two winters' fat loss. After darting and immobilization, data collection takes approximately 10 minutes per elk. In the nutritional assessment, rump-fat thickness is measured with ultrasound; body condition is scored by palpation; pregnancy status is measured by ultrasound and blood sampling; lactation status is determined by inspection of the udder; and body mass is estimated by measurement of heart-girth circumference (Figure 4.). These measurements, when applied to a regression equation developed from captive elk (Cook et al. 2004a), yield estimates of total body fat for each elk. To connect habitat quality to elk condition and pregnancy, we will estimate the forage quality and abundance experienced by each GPS-collared elk for which we also have condition data. We will do this by using the fine-scale plant composition and nutritional quality data to estimate an average forage quality of each of the large-scale habitat types. We will then estimate for each elk a forage quality score by taking a weighted average of each habitat's score, with time spent in each habitat (from GPS locations) as the weighting factor. We will evaluate the influence of habitat quality and selection on elk physiology and pregnancy by using regression models for continuous and discrete response variables.

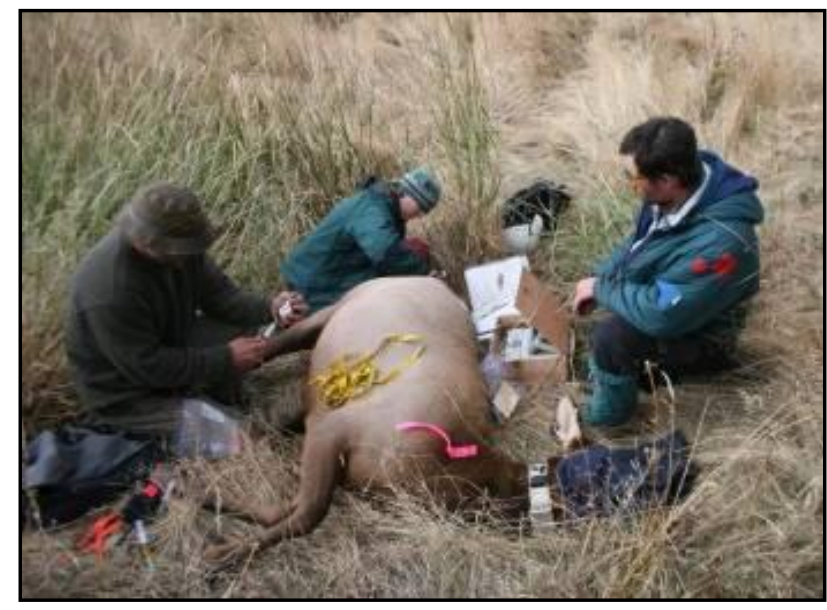

Figure 4.

\section{Elk individual and group behavior}

During winter (January-March), two field crews comprised of two observers each - one working among nonmigratory elk, and one among migrants - will locate elk groups containing those collared individuals for whom we have estimated body condition. Each group will be counted and classified, and site-specific environmental variables will be recorded (e.g., snow depth, distance to timber). Wolf presence/absence and proximity will be determined on-site via telemetry, and retrospectively via time-specific locations from Argos GPS collars. During simultaneous, 15-minute behavioral observations, one observer will conduct a continuous sample to estimate the time budget of the focal individual, while the second observer conducts three instantaneous scan samples to estimate the time budget of the surrounding group. During both focal and scan samples, elk behaviors will be categorized as foraging, vigilant, standing, moving, bedded, bedded vigilant, or other. Behavioral observations of all focal individuals will be conducted once every two weeks, thus facilitating: 1) a well-distributed winter-long sample of each individual's time budget and 2) future evaluation of intra-seasonal behavior changes.

\section{Selected vital rates and additional monitoring}

To estimate the annual survival of adult cow elk, fixed-wing monitoring flights are conducted twice a year - once each in summer and winter - in conjunction with routine monitoring on the ground by WGFD personnel and seasonal field crews. Although we will not directly estimate calf survival in our study due to logistical constraints, we are nevertheless conducting late summer herd composition counts to determine whether a pulse in calf mortality indeed occurs in early summer, as we would predict based on the bear predation rates observed by Barber-Meyer et al. (2008), discussed above.

\section{$\uparrow \quad$ Preliminary Results}

\section{Elk habitat selection}

Although elk collar deployment was primarily completed during 2007 and 2008, we deployed 10 refurbished GPS collars during September 2009 elk body condition recaptures. These collars are scheduled to drop in July 2010, three months later than the drop-off date of the primary sample, and will collect eight locations per day. Therefore, in addition to helping us maintain the project's original sample size, these additional collars will collect valuable movement data during an fourth spring migration period. Meanwhile, the primary group of approximately 60 collars is scheduled to 
drop off in early April. After these collars are retrieved and downloaded, the project's analysis and reporting phase can formally begin.

\section{Elk forage and dietary analyses}

During summer 2009, across both migratory and nonmigratory herd segments, 40 distinct sites in 8 habitat types were sampled for plant community composition and biomass. Subsequently, 135 samples of the most common grass and forb species were sent to labs at the University of Wyoming for nutritional and isotopic analyses. Additionally in summer 2009, fecal samples were obtained from 15 migratory and 15 nonmigratory elk groups for microhistological analyses that will permit insight into elk diet selection at the time of peak forage biomass. Similar plant and fecal sample sizes were obtained during the 2008 sampling season. A complete analysis will commence in spring 2010 once lab results have been obtained, culminating in the completion of a thesis by UW Botany student Sara Beaver.

\section{Wolf movements}

During summer 2009, YNP monitored the movements of wolves in the Druid Peak Pack. Although a GPS collar deployed in this pack failed due to a technical malfunction, YNP obtained weekly locations of VHF-collared wolves (Figure 5.) that will be useful to our project. Furthermore, a GPScollared wolf we captured in Sunlight Basin, WY during winter 2009 dispersed with two additional males into the upper Lamar area of YNP during summer, generating critical information on the wolf exposure of collared migratory Clarks Fork elk. In winter 2010, 11 wolves in four separate packs (Sunlight, Hoodoo, Beartooth, and Absaroka) were captured. Seven of these received GPS collars programmed with three-hour fix rates; and four were fitted with VHF collars. No wolf mortalities occurred, and all collars were functional within the study area by the time of the 2010 winter field season's completion.

\section{Elk body condition recaptures}

The final two of five planned recapture efforts were conducted in September 2009 and March 2010. In September 2009, 21 migratory and 12 nonmigratory cows were captured. Because we obtained a low sample size of lactating migratory cows in September 2008, additional efforts were made to target migratory cows with calves at heel in 2009. During March 2010, 20 migratory and 19 nonmigratory cows were captured. In 2008, the

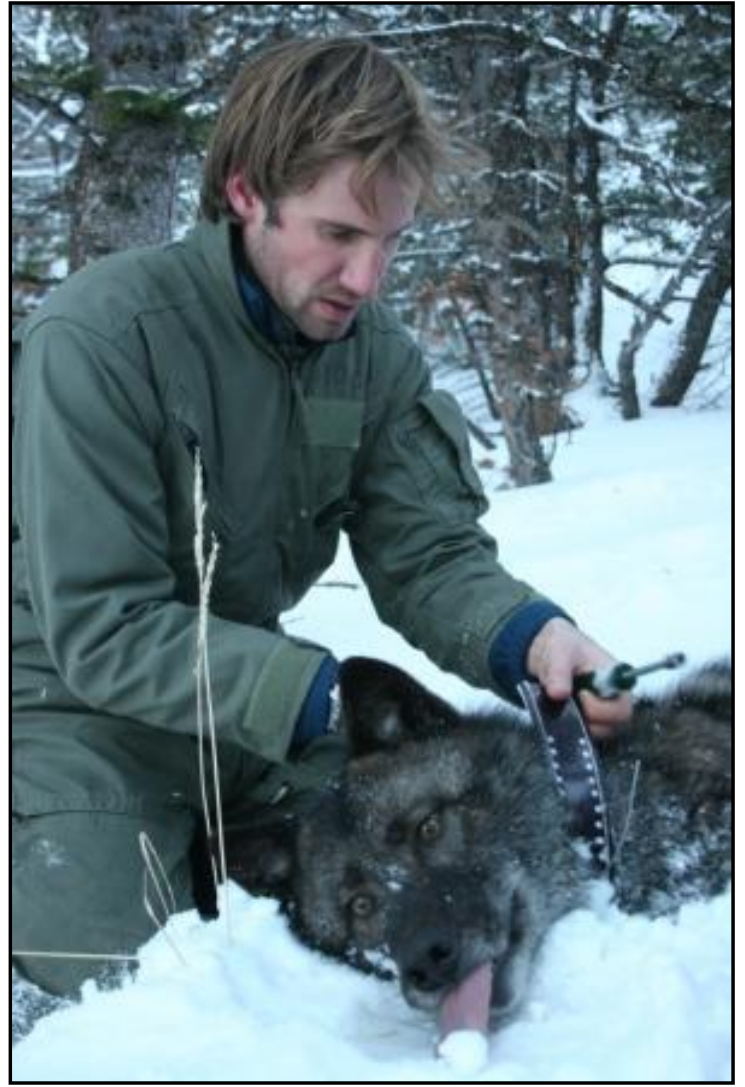

Figure 5.

average percent body fat of migratory elk $(\overline{\mathrm{x}}=$ $5.06 \%)$ and non-migratory elk $(\overline{\mathrm{x}}=6.11 \%)$ did not differ $\left(t_{19}=-0.97, P=0.34\right)$. In winters 2009 and 2010, however, average migratory elk body fat (2009; $\overline{\mathrm{x}}=8.15, n=17$, and 2010; $\overline{\mathrm{x}}=8.00, n=20$ ) was significantly higher $\left(2009 ; t_{31}=2.74, P=0.01\right.$, and 2010; $\left.t_{37}=4.09, P<0.001\right)$ than non-migratory elk body fat (2009; $\overline{\mathrm{x}}=5.34, n=20$, and 2010; $\overline{\mathrm{x}}=$ $4.70, n=19$ ). For summer body-fat comparisons, we pooled data from both years due to low numbers of lactating, migratory individuals $(n=3)$ and nonlactating, non-migratory individuals $(n=3)$ in the 2008 sample. Overall, the percent body-fat of lactating, migratory cows $(\overline{\mathrm{x}}=10.45)$ and lactating, non-migratory cows $(\overline{\mathrm{x}}=10.70)$ was not significantly different $\left(t_{29}=-0.31, P=0.62\right)$, but the percent body fat of migratory non-lactators $(\overline{\mathrm{x}}=17.42)$ was significantly greater $\left(t_{30}=5.11, P<0.001\right)$ than that of non-migratory non-lactators ( $\overline{\mathrm{x}}=12.88$; Table 1$)$.

In March 2010 sampling, a three-year gap in the pregnancy of migratory versus nonmigratory Clarks Fork elk appeared to close substantially, with migratory pregnancy of approximately $80 \%$ and nonmigratory pregnancy approximately $84 \%$. Over 
four winters from 2007 to 2010, pregnancy of migratory elk averaged $67.7 \%(n=68)$, versus $88.7 \%$ $(n=71)$ for non-migratory elk. Comparisons of full and reduced multiple logistic regression models indicate that pregnancy rates are different between migratory and nonmigratory elk $\left(\chi^{2}=9.88\right.$, d.f. $=1, P$ $=0.002)$. Although further discussion is premature, it appears possible that improved forage conditions in summer 2009 are partly responsible for the alleviation of the pregnancy difference between migratory and nonmigratory females.

\section{Elk individual and group behavior}

The project's third and final winter elk behavior study season will conclude on March 31, 2010. Although no summary statistics have yet been conducted, we have obtained a larger number of high-quality individual and group behavior samples than in the two previous seasons. Based on those previous seasons' data, it appears migratory elk spend more time feeding and moving, less time bedded, and no additional time vigilant despite experiencing higher predator densities (Figure 6). This pattern might lend support to a nutritional constraint on migratory elk in preceding summers, and highlights the likely role of the migratory strategy in structuring behavior budgets that are often primarily attributed to the influence of other variables. We look forward to a number of novel and productive analyses relating the behavior and fitness of marked elk to predation and habitat factors, which will shed light on questions important to managers and ecologists alike.

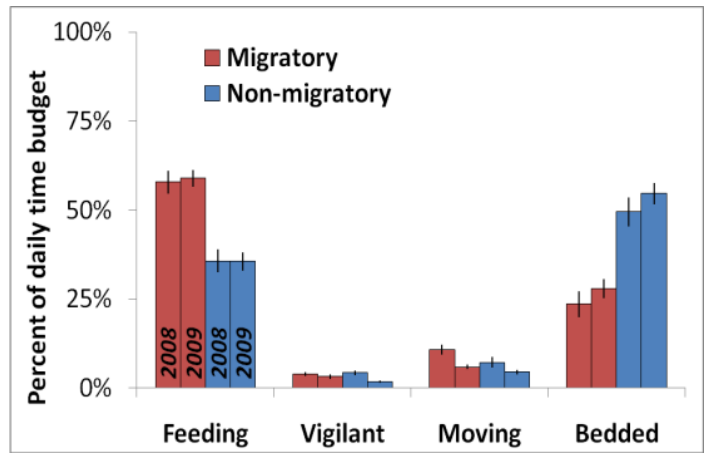

Figure 6. Migratory elk spent more time feeding and moving and less time bedded than non-migratory elk in winters 2008 and 2009. There were no differences in vigilance despite higher wolf densities on migratory range. Comparable data has been collected during winter 2010 .

\section{Selected vital rates and additional monitoring}

A number of mortalities of collared cows were documented in 2009-10. Two mortalities of migratory elk occurred: one inside YNP, most likely in late fall of 2008, and the second in Sunlight Basin prior to the spring 2009 migration. Although no migratory cows were killed during the fall 2009 hunting seasons, four nonmigratory cows were killed by hunters. Low hunting mortality of migratory cows in recent years appears to be related to this herd segment's relatively late returns from YNP summer range to low-elevation winter range.

Migratory recruitment, as measured by winter calf-cow ratios, declined significantly from 1987 to $2009\left(F_{1,22}=74.85, P<0.001\right)$, with estimated coefficients indicating an overall decline of $73.5 \%$. We excluded two years of data (1987 and 1988) from the non-migratory time series due to low sample sizes below 200 individuals. Non-migratory recruitment showed a slight downward trend between 1989 and 2009, but the decline was not significant $\left(F_{1,20}=0.92, P=0.35\right)$. Since 2002, recruitment of the two subpopulations has steadily diverged, with the migratory calf-cow ratio at a near-low of 15 in 2009 and the non-migratory ratio climbing steeply to a near-high in 2009 of 41.

Summer range composition counts indicated that the annual recruitment gap between the subpopulations has developed by early autumn each year, highlighting the importance of factors influencing the summer nutrition of adult females and/or summer survival of calves. On summer range, migratory calf-cow ratios $(\overline{\mathrm{x}}=15, \mathrm{SE}=0.58)$ were lower than non-migratory ratios $(\overline{\mathrm{x}}=39.83, \mathrm{SE}=$ $0.65)$, and these difference were significant $\left(\mathrm{t}_{4}=-\right.$ $28.59, \mathrm{p}<0.001)$. These summer ratios (2007-2009) were based on composition counts of between 250 and 1000 individuals in each population segment.

\section{MANAGEMENT IMPLICATIONS}

The decline of migratory Clarks Fork elk poses several management and conservation challenges. First, the classic seasonal migrations of Clarks Fork elk represent a dwindling phenomenon among North American ungulates and sustain a prized game resource for the state of Wyoming. Second, as the herd's distribution shifts away from YNP, it is likely that wolves and grizzly bears will be drawn into ever-greater conflict with domestic livestock outside of YNP. Third, a primarily nonmigratory population will be increasingly vulnerable to development of the private ranchlands along the Absaroka Front. Finally, the introduction and growth of the wolf population in the study area over the past 
decade has complicated our understanding of elk ecology, and the resulting information gaps could hinder sound management of wolves across the YNP boundary. With higher wolf densities in the habitat of migratory elk, some have argued that the substantial increase in nonmigratory elk is partly a behavioral response of elk seeking to avoid high rates of wolf predation in the backcountry. There is also a public perception, with some empirical support, that the reduced pregnancy rates of Yellowstone migrants could be due to their inability to gain adequate fat reserves on summer range while avoiding wolf predation (Creel et al. 2007). While evidence for these claims is limited, both are likely to influence elk and wolf management policies in YNP, Wyoming, and the other Rocky Mountain states.

Although more thorough discussion of our preliminary results would at this point be premature, we expect that our analyses over the coming two years will offer new insights to managers struggling with these important questions throughout the GYE and beyond.

\section{$\uparrow \quad$ ACKNOWLEDGEMENTS}

In addition to support from the UW-NPS Research Station, this project has received key funding from the Wyoming Game and Fish Department, the Wyoming Animal Damage Management Board, the US Fish and Wildlife Service, the Rocky Mountain Elk Foundation, the Wyoming Governors Big Game License Coalition, and Shoshone National Forest. Design and coordination of the study has benefited from the work of Doug McWhirter (WGFD), Mike Jimenez (USFWS), P.J. White (YNP), Doug Smith (YNP), Christie Hendrix (YNP) and the Cody regional office of WGFD.

\section{$\uparrow \quad$ Literature Cited}

Abrams PA. 1995. Implications of dynamically variable traits for identifying, classifying and measuring direct and indirect effects in ecological communities. American Naturalist 146:112-134.

Bachman G. 1993. The effect of body condition on the trade-offs between vigilance and foraging in Belding's ground squirrels. Animal Behavior, 46:233-244.
Barber-Meyer SM, Mech LD, White PJ. 2008. Elk calf survival and mortality following wolf reintroduction to Yellowstone National Park. Wildlife Monographs 169.

Brown JS, Kotler BP. 2004. Hazardous duty pay and the foraging cost of predation. Ecology Letters 7:999-1014.

Clark CW, Mangel M. 2000. Dynamic state variable models in ecology. Oxford (UK):Oxford University Press.

Cook JG, Johnson BK, Cook RC, Riggs A, Delcurto T, Bryant LD, Irwin LL. 2004a. Effects of summer-autumn nutrition and parturition date on reproduction and survival of elk. Wildlife Monographs, 155:1-61.

Cook RC, Cook JG, Mech LD. 2004b. Nutritional condition of northern Yellowstone elk. Journal of Mammalogy, 85:714-722.

Creel S, Christianson D, Liley S, Winnie J. 2007. Predation risk affects reproductive physiology and demography of elk. Science, 315:960.

Houston AI, McNamara JM. 1999). Models of adaptive behavior: an approach based on state. Cambridge (UK):Cambridge University Press.

Jimenez MD, Woodruff SP, Cain S, Dewey S 2005. Wolf-elk interactions on winter range and state managed feed grounds in Wyoming. 2005 Progress Report. U.S. Fish and Wildlife Service, Jackson, Wyoming.

Krause J, Loader SP, Kirkman E, Ruxton GD. 1999. Refuge use of fish as a function of body weight changes. Acta Ethologica 2:29-34.

Lima SL. 1988. Initiation and termination of daily feeding in dark-eyed juncos: influences of predation risk and energy reserves. Oikos 53:3-11.

Luttbeg B, Rowe L, Mangel M. 2003. Prey state and experimental design affect relative size of trait- and density-mediated indirect effects. Ecology 84:1140-1150. 
McNamara JM, Houston AI. 1987. Starvation and predation as factors limiting population size. Ecology 68:1515-1519.

Pettersson LB, Bronmark C. 1993. Trading off safety against food: state dependent habitat choice and foraging in crucian carp. Oecologia, 95:353-357.

Preisser EL, Bolnick DI, Bernard MF. 2005. Scared to death? The effects of intimidation and consumption in predator-prey interactions. Ecology 86:501-509.

Raithel JD, Kauffman MJ, Pletscher DH. 2007. Impact of spatial and temporal variation in calf survival on the growth of elk populations. Journal of Wildlife Management 71:795-803.

Rudd WJ. 1982. Elk migrations and movements in relation to weather and hunting in the Absaroka Mountains, Wyoming [Thesis]. [Laramie, (WY)]: University of Wyoming.
Schmitz OJ, Krivan V, Ovadia O. 2004. Trophic cascades: the primacy of trait-mediated indirect interactions. Ecology Letters 7:153163.

Smith DW, Drummer TD, Murphy KM, Guernsey DS, Evans SB. 2004. Winter prey selection and estimation of wolf kill rates in Yellowstone National Park, 1995-2004. Journal of Wildlife Management 68:153156.

Sweitzer RA, Berger J. 1992. Size-related effects of predation on habitat use and behavior of porcupines (Erethizon dorsatum). Ecology 73:867-875.

Vehanen, T. 2003. Adaptive flexibility in the behavior of juvenile Atlantic salmon: shortterm responses to food availability and threat from predation. Journal of Fish Biology 63:1034-1045. 